\title{
Ecosin-Mechatron Research Infrastructure - New Multi-Applied Smart and Multi-Applied Cyber - Mix Eco-Systems of Mechatronics in Romania in View of the Internationalization
}

\author{
Gheorghe I. Gheorghe
}

\begin{abstract}
ECOSIN-MECHATRON integrates into major flexibility, national $R \& D$ institutes, technical and polytechnic universities and other companies, NGOs, innovative SMEs and catalysts for advanced smart areas such as Mechatronics and Micro Nano-Mechatronics, Cyber-Mix-Mechatronics, Smart Materials, Robotics and Micro-Nano-Robotics, Mechatronics for Agriculture (Agrotronics), Automotive Mechatronics (Autotronics), Mechatronics of the Industry 4.0 (Indutronics) and so on.

In brief, the ECOSIN-MECHATRON project contributes to attaining the objectives of the National Strategy RDI 2020 in Romania and the Europe 2020 Strategy, respectively increasing the Romanian competitiveness and contribution to the knowledge programs, increasing the role of Mechatronics and Cyber-Mix-Mechatronics in Romania and Europe and increasing the level and efficiency of smart knowledge.
\end{abstract}

Index Terms-smart mechatronic ecosystems and cyber-mixmechatronic systems, multiplicative systems, smart specialized field, eco-nano-technologies.

\section{INTRODUCTION}

Defining the project $<$ ECOSIN-MECHATRON 》 Research Infrastructure - New Multi-Applied Smart and Multi-Applied Cyber-Mix Ecosystems of Mechatronics in Romania in view of the Internationalization.

Project coordinator: National Institute of Research and Development in Mechatronics and Measurement Technique INCDMTM, Bucharest, Romania.

National partners: INCD-ICPE-CA; INCD-IMT; INCD-TP; INCD-INMA; INCD-INOE 2000; INCD-IFLPR; INS-AR; ISSR; INCD-Victor Babeș; IN-Fundeni; Optoelectronica 2001; IPA-CIFAT - Craiova; UPB; U. Gh. Asachi Iași; U. Transilvania - Brașov; U.V. Târgoviște; U. Dunărea de Jos - Galați; U. Ovidiu -Constanța; U. Lucian Blaga - Sibiu; U.T. Cluj - Napoca; U.P. Timişoara; U. Ștefan cel Mare - Suceava; U. Craiova; University of Pitești; UMF Carol Davila - Bucharest; AROTT; etc.

International partners: 4I Institute-Germany, Concordia University - Canada, Fraunhofer Institute - Germany, Steinbeis Foundation- Germany, Unesco Institute-Delft, The Netherlands, International Center for Mechatronics - Linz, Austria, University of Lisbon, Portugal, Technical University from Torino, Italy, TU Wien, Austria, Metz University France.

Manuscript received February 20, 2018; revised April 12, 2018.

Gheorghe I. Gheorghe is with Faculty of Mechatronics Politehnica University of Bucharest, Valahia University of Targoviste an Titu Maiorescu University, Romania (e-mail: geocefin@yahoo.com).
Location of ECOSIN-MECHATRON: location of the coordinator - INCDMTM: Bucharest, Romania: 6-8 Pantelimon, District 2; Web: www.incdmtm.ro; E-mail: incmtm@incdmtm.ro; Phone: (+004)0212520846; Fax: (+004)0212523437.

\section{BRIEF DESCRIPTION}

ECOSIN-MECHATRON - develops the smart specialized field of Eco-Nano-Technologies and Advanced Materials from SNCDI-Romania, through Physical Sciences and Engineering field, correlated and focused with the Mechatronics and Cyber-MixMecatronics scientific field. Due to advances in automation of manufacturing and processes, the mechatronic and cyber-mixmechatronic industry is gaining more and more importance, and its demands result in the need for advanced smart systems. Due to the increasing importance of automation and cybernetization of manufacturing and processes, the field of automation and cybernetization takes on an increasingly important role in industrial processes (smart manufacturing, smart integrated control). The basis of any smart mechatronic and/or cyber-mixmechatronic closed loop control system is to detect the states and variables of a smart manufacturing or data process that are then remotely configured, remotely manipulated and remotely monitored.

Scientific context and relevance: ECOSIN-MECHATRON is relevant in the context of major societal challenges, as this project is being unique to the industrial and economic construction of Romania and to many countries in the world. In Romania, INCDMTM has developed smart and cyber-mixmechatronic systems and products already implemented in the Romanian industry (e.g. at SC Automobile Renault-Dacia, Pitesti). Since 2000, INCDMTM has created and developed other evolutionary engineering branches, such as Integronics and Adaptronics, as scientific steps towards Cyber-Mechatronics and Multi-Applied Cyber-Mechatronics, with adaptations to the new working conditions of the smart industry and of the high performing economy. INCDMTM, collaborates in this smart specialized field with other national institutes, technical and polytechnic universities and other companies, in the fields of Mechatronics and Micro-Nano-Mechatronics; Cyber-Mechatronics and Cyber-Micro-Nano-Mechatronics; Smart Advanced Materials; Mechatronics in Robotics [Robotronics]; Mechatronics in Agriculture 4.0 [Agrotronics 4.0]; Mechatronics in Industry 4.0 [Indutronics 4.0]; Automotive Mechatronics [Autotronics], and so on. ECOSIN-MECATRON contributes to the achievement of the 
objectives of the National Strategy RDI 2020 Romania and of the Europe 2020 strategy, namely general strategic objectives: increasing the competitiveness of the Romanian economy through innovation, increasing the Romanian contribution to the knowledge programs; increasing the role of science in society and specific objectives: increasing the level and efficiency of knowledge in correlation with the public priority: new and emerging technologies.

Degree of implementation in Romania: ECOSIN-MECATRON includes a National Strategic Consortium (Universities and Research Entities), which will expand its strategy at European / international level (with existing Mechatronics and Cyber-MixMechatronics entities in Europe). The implementation steps are: S1 - the development of the National Consortium (achieved) and the International Strategic Consortium (to be achieved); S2 Tendering projects in the fields of RI under national and European programs (partially implemented); S3 - project execution (in progress); S4-Monitoring of construction of equipment related to projects and infrastructure (in progress); S5-Monitoring of national and European project financing (to be achieved); S6-Enrollment of RI in (national and European / International) Networks, completing the National and European Values Chain (to be achieved); S7-value contribution of the RI (to be achieved). RI highlights the achievements already begun, with socio-economic impact, as follows: achieving over 250 smart mechatronic products implemented in the industry (e.g. Automotive Industry - SC Automobile Renault-Dacia, SC Componente Auto Topoloveni, SC Renault Technologie Roumanie, etc.), creation of new jobs (about 220); increasing labour productivity, increasing the quality of manufacturing, etc.

Socio-economic impact: (a) the chronology of events: established in 2010, and based on the POSCCE projects (see section 3 of RI File). The initiative started with the projects won under POSCCE competitions, as early as 2010, for the smart fields: CENTRES: Sedcontrol, Biomecatronica, Certim, Cermiso, Knowledge Transfer and Mechatronic Products.

(b) the type of service they provide or they will provide: industrial and laboratory services; for smart manufacturing services; new and advanced materials; micro-nanotechnologies; automation and cybernetization of manufacturing, etc.

The socio-economic impact in Romania will be sustainable and developed for a Romanian information society with a modern and competitive 4.0 industry and with a smart agriculture, and so on.

The socio-economic impact in the EU and worldwide will be globally sustainable and developed for a society of smart knowledge and a neural society, with smart industries and economies, with superior and performing social, cultural and communication relations and with societal transformations and changes, corresponding to the level of the $21^{\text {st }}$ century.

Unique character of ECOSIN-MECHATRON:

Radical societal changes (industry 4.0 - both smart and cybernetized, agriculture 4.0 - both smart and cybernetized, smart medicine, advanced aerospace industry - mechatronic and cyber-mechatronic systems and technologies for adaptive and multifunctional aerospace systems (e.g. drone systems and networks for agriculture - control of crops and agricultural produce), etc.

ECOSIN-MECHATRON contributes to the achievement of the objectives of the National Strategy for RDI 2020, namely general strategic objectives:

ECOSIN-MECHATRON contributes to the achievement of the main and specific objectives of the National RDI Strategy 2020 at national level and of the Europe 2020 and Europe 2030 Strategy at European / International level.

- Financial information:

Construction and infrastructure costs for the European component: 280 million Euros

Construction and infrastructure costs for the Romanian component: 56 million Euros (of which spent and included in contracted projects: 7.009 million Euros);

Total running costs: 38 million Euros.

Running costs, Romanian contribution: 19 million Euros.

- Representative image:

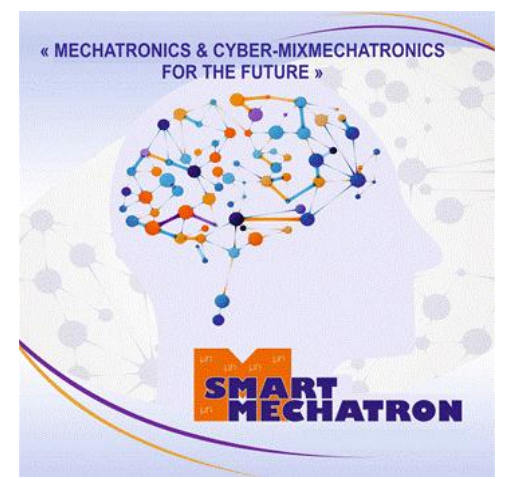

Fig. 1. Brand and Logo of Cyber-MixMechatronics Domain.

\section{CONTENTS OF ECOSIN-MECHATRON}

\section{A. Preamble}

The new smart specialization Mechatronics, Mix Mechatronics and Cyber - MixMechatronics, addresses the philosophy of education in the new Engineering for the Future and the Future Cognitive Society, as well as the holistic multidisciplinary of it.

Depending on the new requirements of the process, product, materials, technology, energy, application and effect in industry, economy and society, this new field has been developed, upgraded and adapted to meet various operational criteria such as reducing material resources, energy and finance, high-level operation, optimal ergonomics, and cost-cutting at the limit.

In this sense, the concept and the evolutionary structure of the smart specialized field develops towards a generative evolution, by adding new structural, functional elements and components and subsystems, based on new principles and adapted to the new scientific discoveries, in order to obtain technical facilities and effects, technological and economic demands required by the concrete applications of smart mechatronic products, technologies and services.

Cyber-mix-mechatronics systems are involved in selective scenarios and variants and in support of their construction, through engineering challenges, as follows:

- selected scenarios on "remote system for monitoring controllers";

- selected scenarios for "actuator detection control system";

- selected scenarios on the "automated traffic control and 
monitoring system";

- selected scenarios on "mobile surveillance system for automobile traffic";

- selected scenarios for the "communication channel monitoring system";

- concept of a "cyber-mechatronic robot system with remote monitoring and remote-control functions" and of modularized systems of programming and coordination in cyberspace;

- concept of a "smart 3D mechatronic system with two grippers and two 3D sensors for measurement, integrated control and industrial services" and of modularized systems of programming and coordination in cyberspace;

- concept of a "cyber-mechatronic technological instrument system with remote monitoring and remote-control functions and of modularized systems of programming and coordination in cyberspace;

- modular structure of a "smart mechatronic and cyber-mechatronic control system of castings in the automotive industry by remote control and remote monitoring" and of modularized systems of programming and coordination in cyberspace;

- concept of "convergence of complexity in cyber-mechatronics";

- "microcontroller programming and interfacing to intelligent mechatronic and cyber-mix-mechatronic systems";

- "smart mechatronic 3D equipment for processes of measurement, control and industrial services";

- "dual three axes smart mechatronic intelligent 3D equipment";

- "creating virtual prototypes that increase the speed of development of mechatronic and cyber-mix-mechatronic machines";

- "conceptual design of the magnetic suspension for the suspension system";

- "structure of a cyber-mix-mechatronic 3D multi-application system with remote monitoring and remote-control functions";

- "magneto-rheological damping system for railway vehicle suspensions";

- etc.

\section{B. Foundation}

It is presented in the original concept, the foundation of the multi-application cyber-mix-mechatronic systems as parts of the physical-cybernetics systems (cyber-physical and intelligent solutions for construction). The paper focuses on the basics of cyber-physical systems supported by the world's great strategists, with specific examples and concepts, with potential societal applications - mechatronic and clatronic intelligent systems, virtual reality systems with some major challenges on reliability and uncertainty, abstraction levels and mismatch physics-cybernetics as well as design software, time-sensitive programming languages and networking for super dense time [1]-[3].

The scientific work exemplifies the creation / realization of multi-application cyber-mixmechatronic systems as parts of global cyber-physical systems.

The Universe of Cyber-Physical Systems (or Physical Cybernetics) includes, in its program of development and implementation, the main stages, step by step, to materialize and implement them in society, to ensure innovative national, European and international strategies for a post knowledge-based and neural society.

Thus, they are based on the "bases of cyber-physical systems" created and grounded by the great strategists of the world regarding:

The concepts of cyber-physical systems (supported by global strategists Christopher Chadwick, Sarah Betzig and Fei $\mathrm{Hu}$ );

The design challenges of cyber-physical systems (supported by global strategists Cameron Patterson, Roger Vasquez and Fei Hu);

Creating mobile cyber-physical systems (supported by global strategists Yeqing Wu and Fei Hu).

Follows the "design principles of cyber-physical systems": $>$ cyber-physical systems controllers (supported by Tony Huynh, Ahmed Alsadah and Fei Hu);

$>$ learning apprenticeship on the Physical-Cybernetic Intelligent System (supported by Kassie McCarley, Joseph Pivscan and Fei $\mathrm{Hu}$ );

> application of HDP-HMM for the dynamic recognition of "hand gestures" (supported by world strategies Lv Wu Ting Zhang and Fei Hu);

$>$ Modelling problems in Cyber-Physics Systems (supported by global strategies Michael Johnson, Tony Randolph and Fei $\mathrm{Hu}$ );

> Modelling Cyber-Physics Systems (Cognitive Vehicles Remote Airplane), (backed by global strategy Meng Cheng Ong, Fei Hu and Yang-Ki Hong);

$>$ Security of Cyber-Physics Systems (supported by Steven Guy, Erica Boyle and Fei Hu);

> Physical Cyber Security Systems - Smart Network example (supported by Rebecca Landrum, Sarah Pace and Fei $\mathrm{Hu}$ ),

Continuing with "Intelligent Sensor Architecture - the basis of Cyber-Physics Systems, on:

$>$ wireless sensors and wireless actuators for applications in Cyber-Physics (supported by Kassie McCarley, Joseph Pierson and Fei $\mathrm{Hu}$ );

$>$ communication detection (supported by Trenton Bennet, John Har and Fei Hu);

$>$ Integrated / Deployed Wireless Microsystem Architecture and Security (supported by Derek Chandler, Jonathan Pittman, Jaber Abu-Qahouq, and Fei Hu);

$>$ the application of a learning machine in physical sensing activity monitoring (Wenlong Tang, Ting Zhong and Edward Sezonov)

Finally, it concludes with "Cyber-Physical Civil Applications" for:

$>$ creating efficient energy (supported by great strategists Preston Arnett, Jan Wolfe and Fei Hu);

$>$ Creating cyber-physical systems for smart grid smart applications (supported by great strategists Matei Rell, Loilim Muirhead and Fei $\mathrm{Hu}$ );

$>$ Creating Video in Unmanned Aircraft for Cyber-Physical Systems (supported by great strategists Meng Cheng Ong, Fei Hu, Yang-Ki Hong, Kenneth Rieks, and Jaber Abu-Qahouq); 


\section{Conception and Realization of Experimental}

Mechatronics and Cyber-mixmechatronics Models

\section{- 3D cyber-mix-mecatronic System ultraprecise multiaplicative for remote control and remote monitoring (Fig. 2) [1], [2], [4].}

According to figure 2, the matrix structure physical (mixmechatronics) and cybernetical (IT\&C) of the system, enables automation, computerization and remote communication, intelligent control and monitoring, thereby contributing to raising the quality level and reducing operating costs specific to the automotive industry.

The $3 \mathrm{D}$ axis system $(\mathrm{x}, \mathrm{y}, \mathrm{z}) 1.1$ with ultraprecise remote control is ordered by PC with specific software 1.4 and 1.5 for the realization of measuring function of a part 1.3 with $3 \mathrm{D}$ ultraprecise probe 1.2. The system is protected with laser protection barrier 1.6 and communicate with special equipment from the electronic unit 1.7 in PLC 2.1 and Internet GPRS 4G. This communication connection is linked with remote control centre 3 provided with a computing station 3.2 and 3.3 connected to the router 3.1 and on which specialized software 3.4 runs.

In the 3D mode of travel, the cyber-mix-mechatronic system is designed to be operated locally using a program preinstalled on PC equipped with display and control software and modelling and emulating remote position. Switching between the two operating modes can be done anytime and measurement (3D control) points may be stored in the memory functioning in the automatic PLC mode. Thus, all these complex functions may be implemented by integrating several functional testing and smart subsystems.
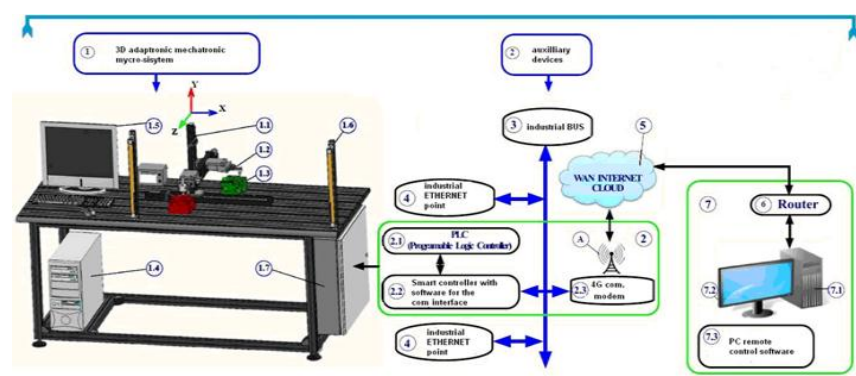

Legend:
1. 3 D cyber-mix-mechatronic system:

1. 3 D cyber-mix-mechatronic system:
1.1 Ultra-precise 3D measuring system / measuring robot / ultra-precise control robot $(x-300 \mathrm{~mm} ; \mathrm{y}=200 \mathrm{~mm} ; \mathrm{z}=250 \mathrm{~mm}$; accuracy:0.1-1nm);

1.2 3D ultra-precise probe (accuracy: 0.1 $\mathrm{nm})$

1.3 Control / measurement part;

1.4 PC local host;

1.5 Display and local user interface;

1.6 Laser protection barrier

1.7 Unit with command system, driving system and telecommunications system;

Fig. 2. 3D cyber-mix-mecatronic System ultraprecise multiaplicative for remote control and remote monitoring

At the same time, this cyber-mixmecatronic system does not require the continued presence of the qualified and costly human operator and aims to ensure operating parameters at nominal values, along with the advantages of cyber technology, such as:

- minimizing operating - troubleshooting time;

- preventive strategies in the operation and maintenance process;

- modularity, flexibility and security.
The 3D multiaplicative cyber-mixmechatronic system, for remote control and monitoring provides connection of remote process stations to one or more central control systems, using various public or private networks for event-driven take-backs caused by an event or cyclical data processing performed using special protocols and effectively managed. The cyber-mixmechatronic system uses one or more software to connect it to the "remote control and monitoring centre" based on modern GPRS technologies and multiple PLCs. The cyber-mixmecatronic system can also do the remote service that offers data exchange via the telephone line or via the Internet and Intranet, using remote equipment and systems such as computers, machines, installations and lines production, error detection, diagnostics, activity optimization, maintenance, repairs, etc.

Thus, the cyber-mixmecatronic system makes significant contributions to minimizing the cost and increasing the efficiency and productivity of industrial activities.

The main system services consist of:

- remote control - system remote control and monitoring;

- remote maintenance, consist of:

- remote monitoring - determining of the status of the system;

- remote diagnosis - identifying the causes of malfunction;

- remote maintenance - eliminating causes;

- acquisition of geometric and mechanical parameters.

- The cyber-mixmechatronic system with remote control and remote monitoring (Fig. 3) [2], [5]

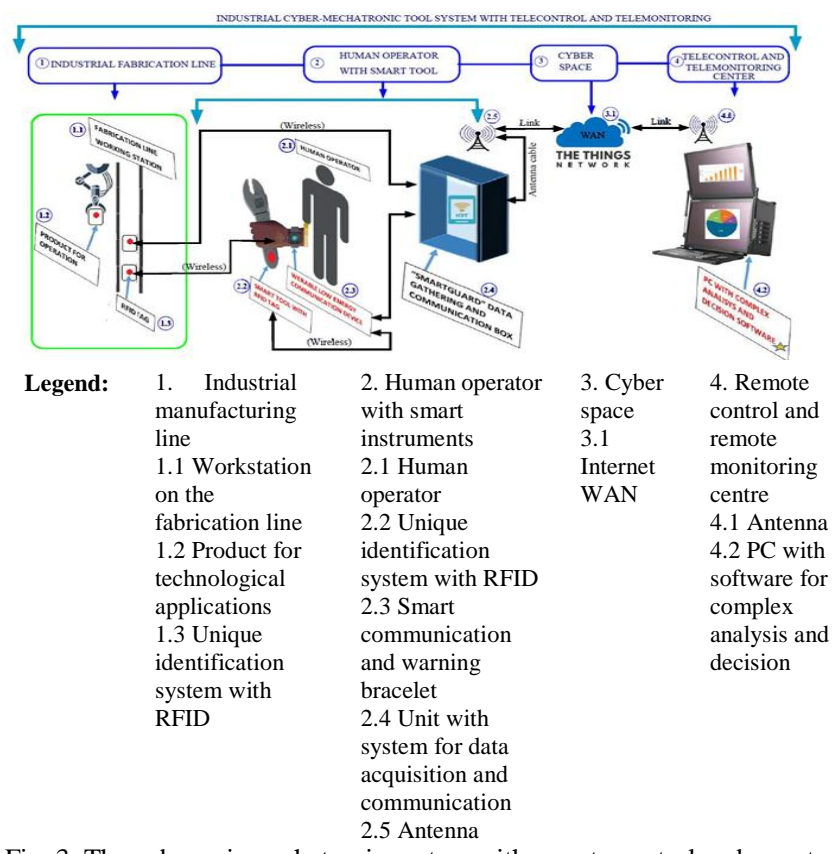

Fig. 3. The cyber-mixmechatronic system with remote control and remote monitoring.

According to Fig 3, the physical (mechatronics) and cybernetics (IT\&C) matrix structure of the system, enables automation and computerization of remote processes (remote control and remote monitoring) of the industrial manufacturing line.

The system performs the function of protecting workstations from human errors specific to fabrication lines (1.1) in the series in the industry, such as automotive parts in the manufacturing industry. Parts (1.2) call feature tags with 
unique ID RFID (1.3) communicating bi-directionally with a drive (2.4) with automation equipment and telecommunication local but also a smart bracelet (2.3) situated on the hand of the operator who is using the device (2.2) equipped with RFID tag and bidirectional communication. Intercommunication between elements listed (part, device, operator) is collected and transmitted using antennas (2.5) and (4.1) through the Internet to a (4.2) computing station at the centre of remote monitoring and remote control (4).

The computer centre remote monitoring and remote control (4.2) running special software designed to synchronize tasks on a database technology and eliminate errors caused by real-time tracking and manufacturing through a comprehensive analysis and forecasts.

- Smart multi-application cyber-mixmechatronic device type industrial robot for remote control and remote monitoring of operational and service processes (Fig. 4) [3], [6].

- According to the fig. 4, the structure of the physical matrix [Mechatronics and Cybernetics (IT \& C)] of the system allows the cybernetization and remote communication of technological operational processes and of processes that service the industry, thus contributing to a higher increase in productivity and of quality of smart industrial. The cyber-mixmechatronic multi-application system performs a remote control and remote monitoring of an industrial robot (1) connected to the cyberspace via the control unit 1.2 and the interface 1.3 with both the internal industrial bus (2.1) and Internet via a 4G GPRS modem. Through this communication connection is made the link to a centre of remote control and remote monitoring (3) provided with a computing station (3.2) and (3.3) connected to the router (3.1) and running specialized software for robot control (3.4).

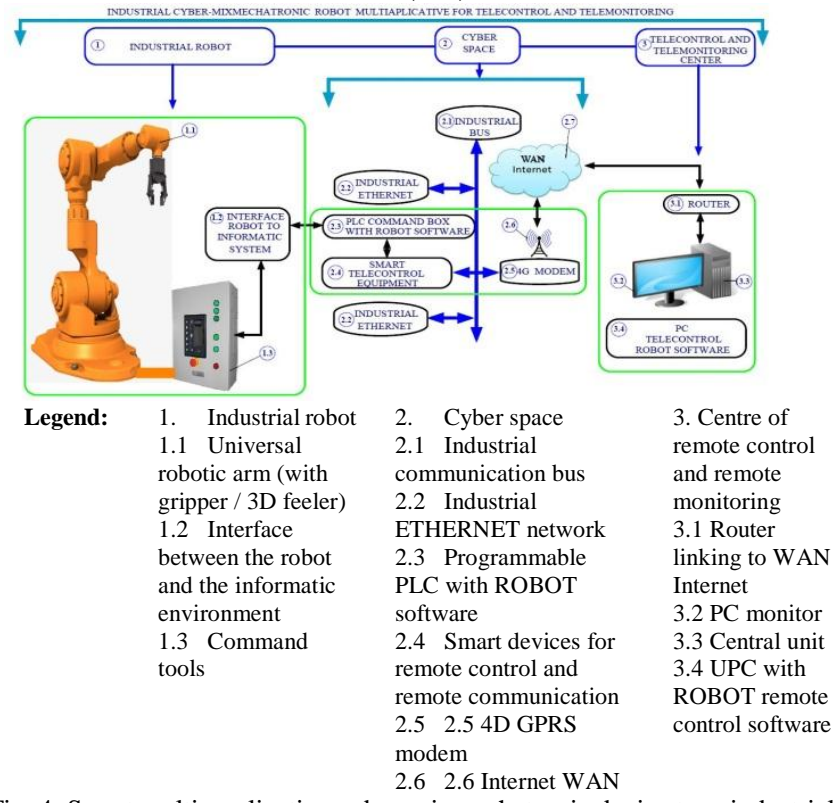

Fig. 4. Smart multi-application cyber-mixmechatronic device type industrial robot for remote control and remote monitoring of operational and service processes.

- Cyber-mixmechatronic system for dampening for automotive and with remote control and remote monitoring functions (Fig. 5) [1], [7].
According to the mentioned figure, the structure of the physical matrix (damper and cybernetics (IT \& C) of the cyber-mixmechatronic system for dampening for automotive allows the smart computerization and cybernetization of the automotive and of the automotive industry, by raising the quality and increasing productivity of the automotive industry.

The cyber-mixmechatronic system for dampening for automotive allows the function of remote monitoring and remote control of a smart damper (1) provided with an electromagnet (1.1) powered by a high voltage source (1.6) in order to modulate the degree of viscosity of the rheologic fluid (1.3).

To obtain information on the global acceleration of the cyber-mechatronic assembly attached to a tire of a vehicle uses the sensor (1.4) and the interface (1.5) connected to an intelligent control and remote-control equipment (1.7).

Internet WAN network connection is performed using a specialized 4G GPRS modem (1.9) provided with an antenna (1.8).

Through this communication connection is made the link to a centre of remote control and remote monitoring (3) provided with a computing station (3.2) and (3.3) connected to the router (3.1) and running specialized software for robot control (3.4)

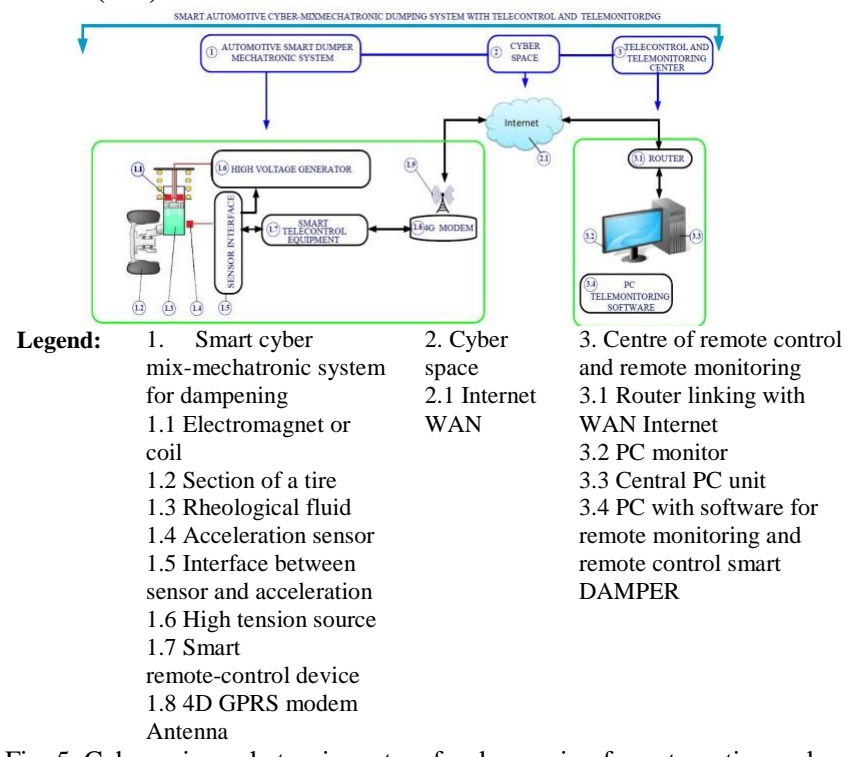

Fig. 5. Cyber-mixmechatronic system for dampening for automotive and with remote control and remote monitoring functions

\section{THE SCIENTIFIC RESUlTS OF MECHATRONIC AND CYBER-MECHATRONIC RESEARCH OBTAINED BY ECOSIN-MECHATRON}

The scientific results obtained in the ECOSIN-MECHATRON infrastructure are synthesized as follows:

- concepts of virtual models in variants and scenarios for mechatronic and cyber-mechatronic systems, with applications in industry (e.g. automobile industry - SC Automobile Renault - Dacia SA Pitesti, SC Auto Components SA Topoloveni, SC Comis SRL Valenii de munte etc) in medicine (e.g. smart mechatronic technologies for selective sintering with laser beam Hospitals in Bucharest, etc.)

- physical models in original solutions for mechatronic and cyber-mix-mechatronics systems with industrial 
applications (e.g. the fine mechanics and mechatronics industry - Mechatronics and Cyber - Mix - Mechatronics Laboratory at INCDMTM Bucharest, for measurements, micro and nano technologies for $\mathrm{PhD}$ thesis, from the Doctoral School of Mechanical Engineering and Mechatronics of UPB and UVT, etc);

- Real parametric values for remote metered and mechatronic systems: remote control, remote monitoring, remote service and remote configuration;

- Process and mechatronic and cyber-mechatronic system validation in real industrial applications;

- Through the realization of "Mechatronic and Cyber-Mix-Mechatronic Systems and Ecosystems developed in the Research Infrastructure "ECOSIN-MECHATRON", the author summarizes the following:

- The creation and development of a new, specialized smart field, that is characteristic of the 21 st century and addressed to it, for ensuring the sustainable development of the national and international economy and industry, the field of Mechatronics and Cyber-Mix-Mechatronics;

- The creation and development of new mechatronic and cyber-mix-mechatronic systems, in original and multi-purpose applications in many industrial, economic and societal environments;

- Substantial contributions to solving the scientific paradigm of Mechatronics, Mix-Mechatronics and Cyber-MixMecatronics;

- Original contributions to research, development and innovation in the intelligent specialized fields of Mechatronics, Mix-Mechatronics (Integronics and Adaptronics) and Cyber-Mix-Mechatronics.

\section{CONCLUSIONS}

"ECOSIN-MECHATRON" Research Infrastructure - New Multi-Applied Smart and Multi-Applied Cyber-Mix Ecosystems of Mechatronics in Romania in view of the internationalization was designed by INCDMTM Bucharest, for the creation, initiation and maturing of a new smart specialized field of Mechatronics and Cyber-MixMechatronics, both in Romania and in the European Union.

The purpose of this new ECOSIN - MECHATRON Research Infrastructure in Romania is to ensure the automation and cybernetization of the integrated technological and process control processes within the intelligent manufacturing industry 4.0 .

The multi-applicability of mechatronic and cyber-mix-mechatronic intelligent systems and micro-nano-systems encompasses industrial and societal areas and areas in many intelligent manufacturing matrices, such as:

- Mechatronics and cyber-mix-mechatronics of the automotive - Autotronics;

- Mechatronics and cyber-mix-mechatronics in the field of agriculture - Agrotronics;

- Mechatronics and cyber-mix-mechatronics in the field of hydraulics - Hydronics;

- Mechatronics and cyber-mix-mechatronics in the field of pneumatics - Pneutronics;

- Mechatronics and cyber-mix-mechatronics in the
Industry - Indutronics.

The ECOSIN - MECHATRON Research Infrastructure will contribute to the accomplishments and development of the overall strategic objectives of the National RDI Strategy 2020 and the Europe 2020 Strategy: Increasing the Romanian contribution through smart knowledge programs, increasing the role of science and engineering in society, and increasing effectiveness of knowledge in correlation with public priority areas.

The first steps of the new research infrastructure have been made: Step 1 - the development of the National Consortium, which has already been carried out; Step 2 - realization of the International Strategic Consortium, being set up and finalized currently, by offering projects in the field of research infrastructure through international projects and programs; Step 3 - actual realization of national and international research projects and programs; Step 4 integration and monitoring of construction and research equipment related to the research infrastructure in progress; Step 5 - managing the national and international funding of projects related to the new research infrastructure - to be carried out; Step 6 - enrolment of the research infrastructure "ECOSIN - MECHATRON" in National, European and International Networks, by completing and integrating the National and International Valuation Chain, and Step 7 valuable and competent contribution of the research infrastructure at national and international level, to be achieved.

The impact of the new "ECOSIN - MECHATRON" research infrastructure at both national and international level will be described by a Romanian knowledge-based and post knowledge-based, with a competitive 4.0 industry and intelligent agriculture corresponding to the level of the $21^{\text {st }}$ century.

\section{REFERENCES}

[1] G. Gheorghe, "Cyber-mixmechatronics engineering," Cefin Publishing House, 2016, ISBN 978-606-8261-24-9;

[2] G. Gheorghe, "Mechatronics and cyber-mechatronics systems," Cefin Publishing House, 2015, ISBN 978-606-8261-22-5;

[3] G. Gheorghe, "Adaptronics micro nano engineering," Cefin Publishing House, 2014, ISBN 978-606-8261-21-8;

[4] J. Machado and J. C. Campos, "Development of dependable controllers in the context of machine design, modern methods of construction design," pp. 125-131, 2014.

[5] G. Saikalis et al., "Virtual embedded mechatronics system," SAE Technical Paper, 2006, ISBN: 2006-01-0861;

[6] B. T. Fijalkowski, "Automotive mechatronics: Operational and practical issues," Springer Publishing House, vol. 3.

[7] K. Zhou, C. Ye, J. Wan et al., "Advanced control technologies in cyber-physical system," in Proc. 5th International Conference on Smart Human - Machine Systems and Cybernetics (INMSC), Aug. 2013, DOI: 10.1109/INMSC.2013.284;

[8] M. Silva, F. Pereira, F. Soares et al., "An overview of industrial communication network, new trends in mechanism and machine science from fundamentals to industrial applications", vol. 24, pp. 933-940, 2015.

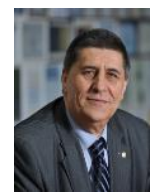

Gheorghe Gheorghe is an associate professor at the Faculty of Mechatronics Politehnica University of Bucharest, Valahia University of Targoviste an Titu Maiorescu University, Romania. He received his bachelor degree in precision mechanics from Politehnica University of Bucharest, doctoral degree at Politehnica University of Timisoara and Doctor Honoris Causa degree from Valahia University of Targoviste, His current research includes mechatronics and cyber-mechatronics systems, measurement technique, cyber - adaptronics systems. 